Веслополова Дарья Сергеевна

студент кафедры «Финансы и кредит»

Дальневосточного федерального университета

\section{РЫНОК ВЕНЧУРНЫХ ИНВЕСТИЦИЙ РОССИИ: ПЕРСПЕКТИВЫ И ПРОБЛЕМЫ РАЗВИТИЯ}

Veslopolova Daria Sergeevna

Student, Finance and Credit Department, Far Eastern Federal University

\section{VENTURE INVESTMENT MARKET IN RUSSIA: DEVELOPMENT PROSPECTS AND PROBLEMS}

\begin{abstract}
Аннотация:
В данном исследовании раскрывается значимость венчурного бизнеса как ключевого фактора, влияющего на экономическое развитие России. В условиях существующего экономического кризиса венчурные фонды яөляются значимым институтом, способствующим доведению финансовых ресурсов до молодых инновационно активных компаний. Проведен анализ динамики отечественных венчурных вложений. Рассмотрены проблемы и перспективы развития венчурного рынка РФ. Предлагаются мероприятия, способствующие улучшению инду стрии венчурного бизнеса. Сделан вывод, что поддержка рынка венчурных вложений в России выступает одним из важных и актуальных направлений государственной инновационной политики и необходимым фактором активизации инновационного процесса и повышения конкурентоспособности отечественной промышленности. Россия сможет реализовать свой инновационный потенциал, сократить технологическое отставание, совершить переход к инновационной экономике только в случае объединения усилий профессионального бизнеса и государства в области построения национальной системы венчурного инвестирования.
\end{abstract}

Ключевые слова:

венчурные инвестиции, венчурные фонды, высокие технологии, высокорискованные проекты, инновации.
Keywords: venture investments, venture funds, high tech, highrisk projects, innovations.

В процессе глобализации границы между различными видами финансовых институтов продолжают стираться, они становятся системой мобилизации финансовых ресурсов и их перераспределения в мировом масштабе, оказывая все большее влияние на сферу производства и торговли. Продолжение интеграции и конвергенции фринансовых секторов экономик стран способствует появлению принципиально новых инновационных товаров, информационных технологий, IT-решений, приводит к возрастанию конкуренции субъектов рынка за доступ к капиталу. Таким образом, финнансовая глобализация открывает новые возможности для развития национальных экономик, поскольку одновременно с финансовыми потоками, вращающимися между государствами, происходит перемещение новых технологий, модернизируя экономику и финансы в странах мира. Превращение российского финансового рынка в активного участника мировой финансовой системы возможно только при высокой степени его интеграции в мировой рынок, следовании тенденциям прогресса последнего. Рассмотрим развитие рынка венчурных инвестиций России как части мирового хозяйства.

К настоящему времени в РФ сформировалась тенденция технологического отставания страны (усугубившаяся кризисом 2014 г.) и ограниченности вовлечения в мировую технологическую революцию. Наблюдаются проблема отсутствия налаженной системы финансирования инновационной деятельности предприятий и недостаточность развития венчурной индустрии. Привлечение в высокотехнологическую сферу экономики нашего государства внебюджетных вложений (венчурных) будет способствовать решению вопросов технологического отставания от развитых стран Запада, переходу российской экономики от сырьевой направленности к инновационной, реализации инновационного потенциала отдельных регионов [1]. 
Венчурные фонды (или VC-фонды, от англ. - venture capital fund) являются главным институтом, способствующим увеличению числа новых фондов [2]. Несмотря на их возрастающее количество (в 2017 г. прослеживался приток новых игроков - появилось 17 новых венчурных фондов, 4 из которых - фонды с участием государственного капитала), объем их совокупного капитала за период с 2012 по 2016 г. уменьшался, но за 9 месяцев 2017 г. отмечен прирост капитала в сравнении с показателями 2016 г. Эту динамику можно проследить на рисунке 1. С 2014 по 2016 г. в России с учетом обесценивания рубля темпы прироста совокупного капитала венчурных фондов существенно снижались. Инвесторы придерживались более осторожной инвестиционной стратегии, что послужило причиной дальнейшего уменьшения среднего размера инвестиций. За 9 месяцев 2017 г. темп роста совокупного объема капитала венчурных фондов был равен $+18 \%$, в 2016 г. отток составил $-5,5 \%$, в 2015 г. $-11,7 \%$. Например, в 2013 г. это значение равнялось $+24,6 \%$. В 2013 г. был достигнут максимум совокупного капитала в объеме 4635 млн долл.

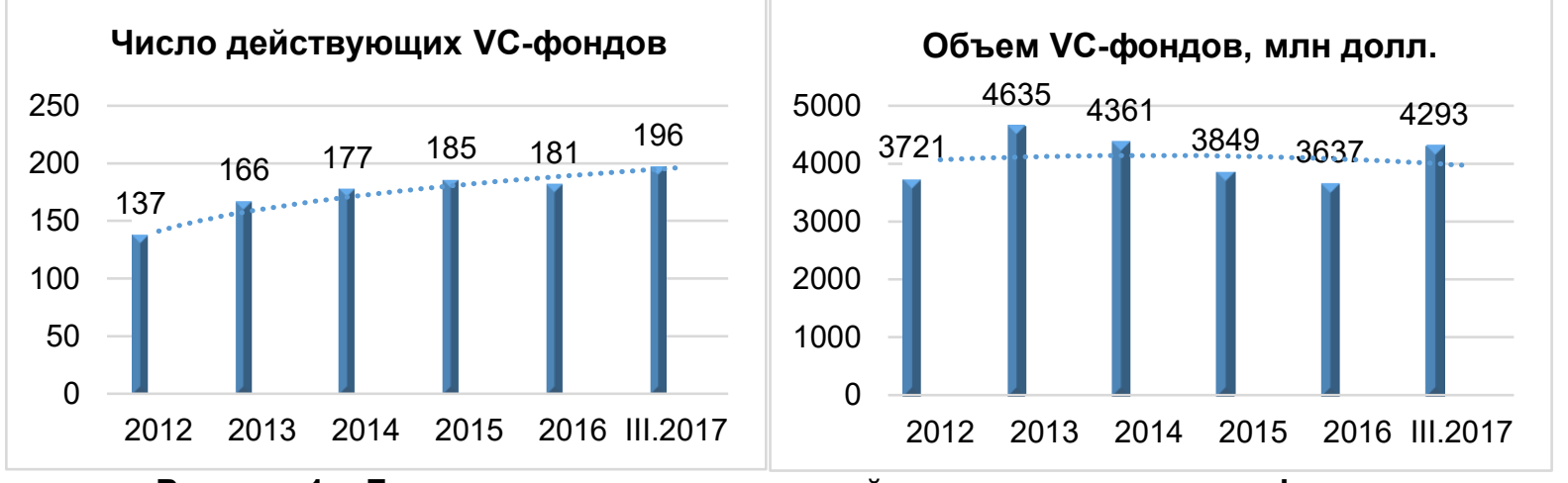

Рисунок 1 - Динамика прироста числа действующих венчурных фондов и объема капитала венчурных фондов в 2012-2017 гг. [3]

В 2017 г. наблюдался прирост венчурных инвестиций в российские высокорискованные проекты от венчурных фондов и «бизнес-ангелов» [4]. Достаточно большой объем вложений (948 млн долл. за три квартала 2017 г.) объясняется значительной ролью государства как крупнейшего игрока на рынке. На его долю приходится 29 \% от всего количества действующих фондов. Более того, фонды с участием капитала государства остаются доминирующим источником поступления инвестиций для компаний, не занимающихся IT-деятельностью (89 \% фондов сфокусированы на вложениях в реальный сектор экономики или имеют смешанные отраслевые предпочтения). Для частных фондов наибольший интерес представляют компании сектора информационно-коммуникационных технологий. На его долю пришлось около 78 \% от общего объема венчурных инвестиций. Среди лидеров по привлечению ресурсов выделяется Центральный федеральный округ, имеющий 74 \% по объему и 65 \% по числу. Также прослеживается увеличивающаяся инвестиционная активность Северо-Западного и Приволжского федеральных округов.

Активность VC- и PE-фондов (от англ. private equity fund - фонд прямых инвестиций) по выходам, т. е. по количеству компаний, из которых были осуществлены выходы, в течение 2016 г. почти достигла аналогичного значения 2015 г. - 46 выходов против 50. При этом около $91 \%$ числа выходов «обеспечили» VC-фонды (в 2015 г. доля достигала 68 \%), из которых 71 \% - это VC-фонды с участием государственного капитала (44 \% в 2015 г.).

В условиях существующего экономического кризиса в России венчурные фонды являются достаточно важным институтом, способствующим доведению денег до молодых инновационно активных компаний, в результате увеличивается интерес к инновациям на примере начавшегося сотрудничества с Российской венчурной компанией (далее - РВК). Необходимо осуществлять мероприятия, направленные на увеличение частных вложений в венчурный сектор экономики (например, обращаться к опыту стран, которые используют льготу на налог на прибыль от вложения средств в малые инновационные предприятия) [5].

Успешное развитие российской индустрии венчурного инвестирования невозможно без оказания фринансовой поддержки инновационным компаниям на этапе их создания [6]. Мировой опыт доказывает, что наиболее интересны для «бизнес-ангелов» предприятия именно на этапах становления. «Бизнес-ангелы» в настоящее время приобретают все большее значение в данном сегменте экономики. В 2015 г. количество их вложений возросло на $34,1 \%$, не считая синдицированных сделок, рост продолжился в 2016 и 2017 гг. [7].

Благодаря скоординированной работе «бизнес-ангелов» и предпринимателей-инноваторов венчурные фонды могут выбрать наиболее перспективные и выгодные стартапы предприятий для своих портфелей. Круг российских «бизнес-ангелов», регулярно вкладывающих деньги, 
достаточно мал, он ограничивается, по разным оценкам, от 150 до 200 человек. Развитие подобного инвестирования будет способствовать появлению на рынке большего количества стартапов, а также обеспечивать тщательный отбор инвестиционных компаний со стороны фондов. Данные действия гарантируют привлечение на рынок венчурного инвестирования нового капитала [8].

Для эфрфективного и успешного развития высокотехнологичной области экономики государство должно иметь единую политику по отношению ко всем структурам, которые действуют в инновационной среде: бизнес-инкубаторам, особым экономическим зонам, технологическим паркам, РВК, «Роснанотех» и др. Важно скоординировать усилия в этой сфере. Необходимы нововведения, реализуемые с помощью РВК. Актуальным остается создание в Российской Федерации венчурных инвестиционных фондов новой организационно-правовой формы - инвестиционных товариществ. Благодаря им можно повторить наиболее распространенную во всем мире форму юридической организации венчурных фондов - ограниченного товарищества. Учреждение данных фондов будет способствовать привлечению отечественных и иностранных инвесторов к регистрации новых фондов именно в России.

Необходимо проводить и другие мероприятия, направленные на усиление инвестиционной активности как в РФ в целом, так и на рынке венчурного инвестирования в частности. Подобные меры прежде всего связаны с проработкой защиты собственности, диффреренцированного налогообложения при осуществлении инновационной деятельности, снижения единого социального налога для IT-компаний, судебной системы, совершенствования законодательства, упрощения требований к регистрации венчурных инвестиций, перехода на уведомительную систему регистрации. Россия сможет реализовать свой инновационный потенциал, уменьшить технологическое отставание, совершить переход к инновационной экономике только в случае объединения усилий профессионального бизнес-сообщества и государства в области построения национальной системы венчурного инвестирования [9].

Для достижения перехода экономики РФ от сырьевой направленности к инновационной важно грамотно использовать финансовые инструменты и рычаги для привлечения в высокотехнологическую область экономики внебюджетных инвестиций. Венчурное инвестирование - одно из самых главных способов реализации высокорискованных инновационных проектов. РФ обладает более чем 10-летним опытом в данной сфере, но венчурная деятельность не приобрела достаточного уровня зрелости. Еще рано говорить о том, что российский капитал лежит в основе национального сектора венчурных вложений. Поддержка рынка венчурных инвестиций в России является одним из важных и актуальных направлений государственной инновационной политики и необходимым фрактором активизации инновационного процесса компаний (малых, средних, крупных) и повышения конкурентоспособности отечественной промышленности.

Российская Федерация обладает огромными перспективами реализации высокорискованных инновационных проектов. Главным образом венчурные инвесторы интересуются вложением капитала в создание и развитие новых технологий, малый бизнес. (Малый бизнес пользуется бо́льшим спросом у инвесторов, нежели крупный, по нескольким причинам: малые предприятия оперативно и гибко подстраиваются под изменения конъюнктуры рынка и адаптируются к его требованиям. Это происходит за счет того, что они располагают небольшими объемами производства, риск потерь при переходе к новым технологиям меньше, чем у крупных игроков. Также небольшие фрирмы, как правило, занимаются научными исследованиями и разработками в тех сорерах, которые являются рискованными и неперспективными для крупных компаний. Чтобы разработать и довести до потребителей инновационный продукт, малому предприятию требуется на треть меньше времени по сравнению с холдингами, имеющими сложную структуру управления.) Именно эти секторы экономики являются объектами рисковых инвестиций [10].

Важным аспектом улучшения индустрии венчурного инвестирования выступает привлечение новых источников капитала на венчурный рынок РФ. Кроме частных инвестиций, большим потенциалом обладают иностранные источники финансирования, которые в настоящий момент менее доступны вследствие макроэкономической обстановки. Чтобы заинтересовать зарубежных инвесторов и стимулировать их к вложению капитала в российские компании, необходимо повышать инвестиционную привлекательность инновационных предприятий, ориентированных прежде всего на глобальные рынки, получающих выручку в валюте, но несущих затраты в рублях. Такие компании могут свободно подстраиваться под целевые зарубежные рынки, принося нелинейно значительную прибыль с минимальными издержками [11].

Для повышения эффективности рынка венчурных инвестиций России и привлечения в этот бизнес национальных капиталов постоянно возникает вопрос развития системы венчурного финансирования. Это в свою очередь приводит к задаче совершенствования нормативно-правового 
регулирования для улучшения инвестиционно-инновационного инструментария в целях увеличения оборотного капитала компаний и выпуска инновационной конкурентоспособной продукции на отечественный и мировой рынки [12].

\section{Ссылки и примечания:}

1. Гаврилова Ж.Л. Проблемы модернизации и перехода к инновационной экономике [Электронный pecypc]. URL: http://www.m-economy.ru/art.php?nArtld=3569 (дата обращения: 10.01.2018)

2. См. обзоры рынка прямых и венчурных инвестиции в России за 2016 и 9 месяцев 2017 г. URL: http://www.rvca.ru/rus/resource/library/rvca-yearbook (дата обращения: 10.01.2018).

3. Составлено на основе данных обзоров рынка прямых и венчурных инвестиций.

4. См. обзоры рынка прямых и венчурных инвестиции в России за 2016 и 9 месяцев 2017 г.

5. О государственно-частном партнерстве, муниципально-частном партнерстве в Российской Федерации и внесении изменений в отдельные законодательные акты Российской Федерации [Электронный ресурс] : федер. закон от 13 июля 2015 г. № 224-Ф3. Доступ из справ.-правовой системы «КонсультантПлюс».

6. Artie W.N., Macbeth D., Yip L.S.C. Exploring performance drivers for technology-based ventures from early stage to expansion: perspectives of venture capitalists // Venture Capital. 2017. Vol. 19, no. 4. P. 335-359.

7. См. обзоры рынка прямых и венчурных инвестиции в России.

8. Пшеничников P.С. Практика венчурного инвестирования в Российской Федерации [Электронный ресурc]. URL: http://sibac.info/conf/econom/xxxii/35389 (дата обращения: 10.01.2018); Селезнева М.М. Венчурное фринансирование в России: венчурные фонды и бизнес-ангелы // Приволжский научный вестник. 2015. № 4-1 (44). С. 87-90.

9. Панягина А.Е. Развитие механизмов венчурного финансирования в России // Современная экономика: проблемы, тенденции, перспективы. 2012. № 7.

10. Там же.

11. Artie W.N., Macbeth D., Yip L.S.C. Op. cit.

12. Гаврилова Ж.Л. Указ. соч.

\section{References:}

Artie, WN, Macbeth, D \& Yip, LSC 2017, 'Exploring performance drivers for technology-based ventures from early stage to expansion: perspectives of venture capitalists', Venture Capital, vol. 19, no. 4, pp. 335-359. https://doi.org/10.1080/13691066.2017.1334302

Gavrilova, ZhL 2018, Problems of modernization and transition to an innovative economy, viewed 10 January 2018, <http://www.m-economy.ru/art.php?nArtld=3569>, (in Russian).

Panyagina, AE 2012, 'Development of venture financing mechanisms in Russia', Sovremennaya ekonomika: problemy, tendentsii, perspektivy, no. 7, (in Russian).

Pshenichnikov, RS 2018, Venture investment practice in the Russian Federation, viewed 10 January 2018, <http://sibac.info/conf/econom/xxxii/35389>, (in Russian).

Selezneva, MM 2015, 'Venture financing in Russia: venture funds and business angels', Privolzhskiy nauchnyy vestnik, no. 4-1 (44), pp. 87-90, (in Russian). 